\title{
Are the Autistic People at the COVID-19 Risk Group? An Applied Plausibility to Dental Health
}

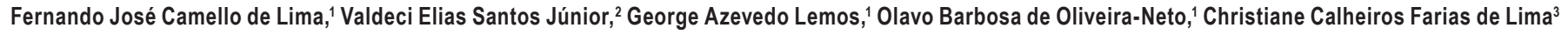

${ }^{1}$ Anatomy Division, Institute of Health and Biological Sciences, Federal University of Alagoas, Maceió, AL, Brazil

${ }^{2}$ School of Dentistry, Federal University of Alagoas, Maceió, AL, Brazil

${ }^{3}$ Rehabilitation Center III, State University of Health of Alagoas, Maceió, AL, Brazil

- Conflicts of interest: none declared.

\section{Dear Editor,}

$\mathrm{S}$ ars-CoV-2, the virus that causes COVID-19, the agent responsible for the 2020 pandemic, can develop severe clinical conditions, increasing the risk of death in the elderly and in people with comorbidities, such as: diabetes, immunosuppressive diseases, hypertension, and some others. This is justified by the low organic resistance to the inflammatory process developed by COVID-19, especially when it triggers a "cytokine storm", which specially compromises the lungs, heart, kidneys and even increasing the risks of thrombosis and secondary infections by fungus and bacteria. However, the risk of autistic people will be justified under behavioral and biological aspects. ${ }^{1-4}$

As well as in other viral infections, the higher the host's viral load is, the greater the risk of developing a more serious disease, considering that Sars-CoV-2 enters in cells carried by type 2 cytoplasmic receptors, the angiotensin converters (ACE- 2), abundantly found in the epithelial cells of the oral and nasal mucosa, and also considering that there is evidence that people within the autism spectrum have a greater number of these receptors, ${ }^{5}$ it is suggested that there is biological plausibility for autistic individuals, when contracting Sars-CoV-2, to be at a higher risk of developing the severe form of COVID-19. ${ }^{6}$

It is important to highlight that most people within the autism spectrum need help to develop their daily activities, ${ }^{7}$ which makes the practice of social isolation more difficult, especially some components of the affected family. During the quarantine period, a lot of people had their own routines changed, but for autistic people, in addition to that, there was also a discontinuity in their face-to-face therapies, making them even more vulnerable to behavioral changes, because of that, some may become less cooperative with the guidelines given to them. ${ }^{8,9}$

Considering that all changes that occur abruptly, and without any prior and structured preparation, may reduce tolerance levels, as sensitivity and anxiety increase, with an exacerbation of anxiety, there will be also an increment of stress and serum cortisol levels, providing conditions for an immunosuppression, which combined with behavioral factors (stress), provides a reduction in concentration (focus) and, consequently, making them less cooperative to the requests made by their caregivers, for example, not practicing a good virus threat etiquette, including: not accepting to use masks, sneezing without covering the nose and touching their eyes, mouth and nose with contaminated hands. ${ }^{10-12}$

Out of a routine, sometimes performed for years, some people on the autism spectrum may be uncomfortable, and seek to stimulate themselves, for example by performing stereotyped movements, self-mutilation and loss of good habits that had been acquired, ${ }^{13,14}$ such as brushing their own teeth alone or calmly allow others to do it, in addition to possible changes in their eating habits, increasing the frequency of consumption of sugary foods to occupy the most idlest time, providing for some, a pleasant tranquility that was lost along with their old routine..$^{10,15-17}$

It is worth mentioning that in this context, which combines a reduction in the oral hygiene quality, an increase in sugar consumption and the need for social isolation, during the COVID-19 pandemic period, or while Sars-CoV-2 is circulating, the risk of infection by this virus, during dental care, ${ }^{18}$ will be greatly increased, both for preventive actions and for therapeutic interventions, consequently with less access to dentists, the altered routine will provide an increase of stress, and as a possible consequence, there may be an increase in the demand for sweet food, unconsciously seeking to increase the endorphins levels, generating a reassuring pleasure, however, with the risk of caries incidence, which can even be aggravated if there is little awareness of family members about the importance of taking care of oral hygiene, because less collaborative behavior is already expected for some people on the autism spectrum. ${ }^{15,19}$ 
Therefore, the effects of the pandemic on some people on the autism spectrum may compromise gains obtained in face-to-face therapies, given that many of them needed to be put at hold. ${ }^{12,15}$ Already-established life routines were suddenly modified, providing the emergence of other compensatory behaviors, exposing them to psychic risks, such as new stereotypes, and physical ones, such as caries, gingivitis, and even the possibility of developing a serious form of COVID-19 if exposed to Sars-CoV-2, for example during dental care,$^{18}$ considering the possibility of having a greater amount of ACE-2 in autistic people (Figure 1).
However, although there was already a hypothesis raised about the risk of the autistic people developing COVID-19 from the behavioral aspect, ${ }^{20}$ the biological aspect of this risk hasn't been explored, just as we have difficulty in finding data in the literature about autistic people with COVID-19. Thus, we hope to have warned the scientific community to seek evidence to confirm or refute the hypothesis that autism fits the profile of people at risk of developing the severe form of COVID-19, with the additional fact that they don't always know how to inform their symptoms, increasing the risk of severity of COVID-19.

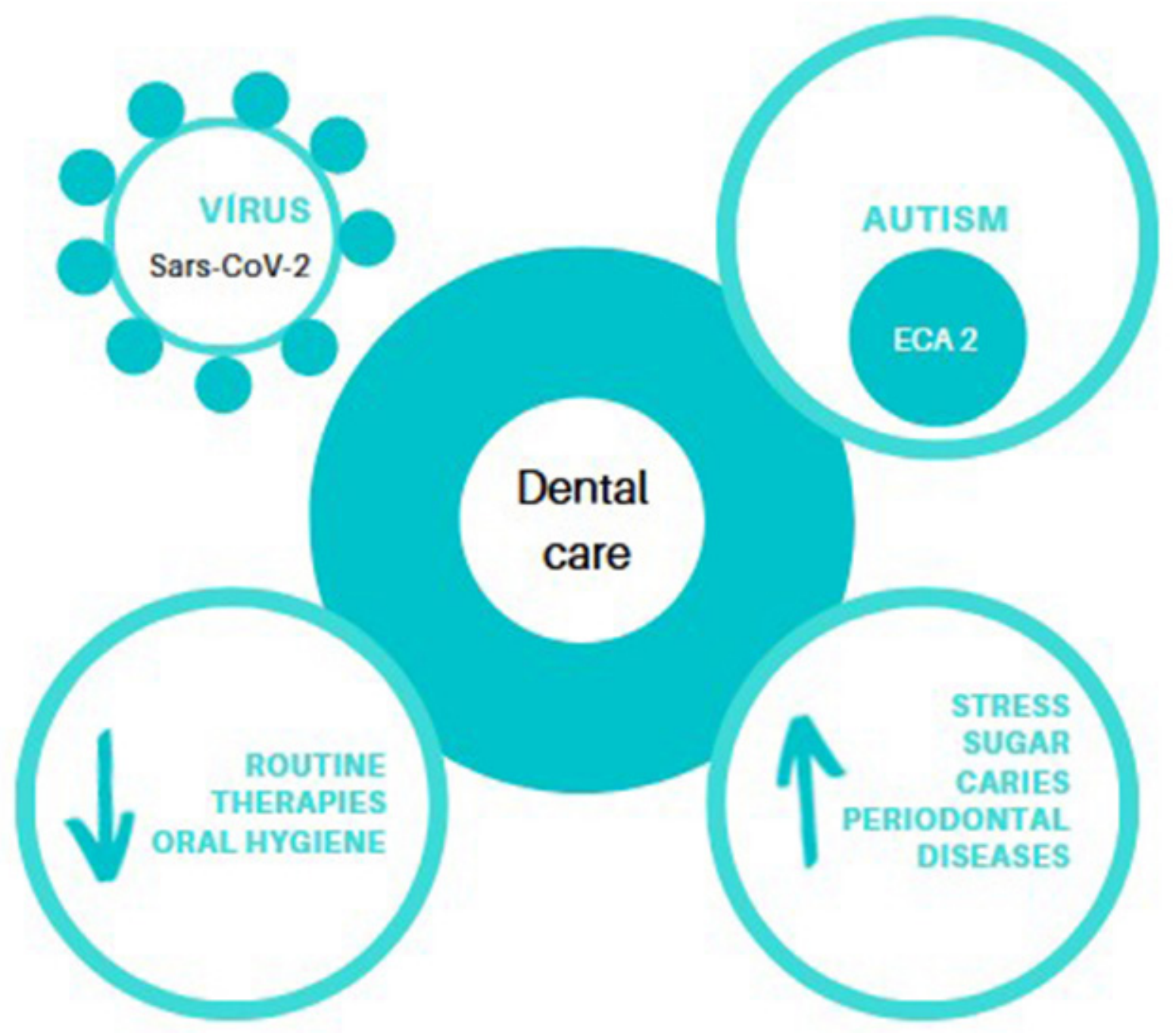

Figure 1. Risk factors for COVID-19 in autistic people. Abbreviations: ACE-2 (Angiotensin-converting enzyme 2) 


\section{References}

1. Sardu C, Gambardella J, Morelli MB, Wang X, Marfella R, Santulli G. Hypertension, Thrombosis, Kidney Failure, and Diabetes: Is COVID-19 an Endothelial Disease? A Comprehensive Evaluation of Clinical and Basic Evidence. J Clin Med. 2020;9(5):1417.

2. Ye Q, Wang B, Mao J. The Pathogenesis and Treatment of the 'Cytokine Storm' in COVID-19. J Infect . 2020;80(6):607-613.

3. Rawson TM, Moore LSP, Zhu N, Ranganathan N, Skolimowska K, Gilchrist $\mathrm{M}$, et al. Bacterial and Fungal Co-Infection in Individuals With Coronavirus: A Rapid Review to Support COVID-19 Antimicrobial Prescribing Clin Infect Dis . 2020;ciaa530.

4. Beigmohammadi TM, Jahanbin B, Safaei M, Amoozadeh L, Khoshavi M, Mehrtash V, et al. Pathological Findings of Postmortem Biopsies From Lung, Heart, and Liver of 7 Deceased COVID-19 Patients. 2020;1066896920935195. 5. Firouzabadi N, Ghazanfari N, Shoushtari AA, Erfani N, Fathi F, Bazrafkan M, et al. Genetic Variants of Angiotensin-Converting Enzyme Are Linked to Autism: A Case-Control StudyPLoS One. 2016;11(4):e0153667.

6. Sajdel-Sulkowska EM, Makowska-Zubrycka M, Czarzasta K, Kasarello K, Aggarwal V, Bialy $M$, et al. Common Genetic Variants Link the Abnormalities in the Gut-Brain Axis in Prematurity and Autism. Cerebellum. 2019;18(2):255-265.

7. Krämer K, Gawronski A, Vogeley K. Diagnosis and Therapeutic Interventions in Autism Spectrum Disorders in Adulthood Fortschr Neurol Psychiatr. 2016;84(9):578-88.

8. To KKW, Tsang OTY, Leung WS, Tam AR, Wu TC., Lung DC, et al. Temporal profiles of viral load in posterior oropharyngeal saliva samples and serum antibody responses during infection by SARS-CoV-2: an observational cohort study. Lancet Infect Dis. 2020;20(5):565-574.

9. Kilincaslan A, Kocasa S, Bozkurta S, Kayaa I, Derina S, Aydinb R. Daily living skills in children with autism spectrum disorder and intellectual disability: A comparative study from Turkey. Research in Developmental Disabilities. 2019;85:187-196
10. Randell E, McNamara R, Delport S, Busse M, Hastings RP, Gillespie D, et al. Sensory Integration Therapy Versus Usual Care for Sensory Processing Difficulties in Autism Spectrum Disorder in Children: Study Protocol for a Pragmatic Randomised Controlled Trial. Trials. 2019;20(1):113.

11. Amos GA, Byrne G, Chouinard PA, Godber T. Journal of Autism and Autism Traits, Sensory Over-Responsivity, Anxiety, and Stress: A Test of Explanatory Models Developmental Disorders. 2019;49:98-112

12. Mudd PA, Crawford JC, Turner JS, Souquette A, Reynolds D, Bender D, et al. Targeted Immunosuppression Distinguishes COVID-19 From Influenza in Moderate and Severe Disease. medRxiv. 2020:30;2020.05.28.20115667.

13. Rice C, Schendel D, Cunniff C, Doernberg N. Public Health Monitoring of Developmental Disabilities with a Focus on the Autism Spectrum Disorders. Am J Med Genet C Semin Med Genet. 2004;125C(1):22-7.

14. Souza NCS, Mendonca JN, Portari GV, Jordao Junior AA., Marchini JS, Chiarello PG. Intestinal Permeability and Nutritional Status in Developmental Disorders. Altern Ther Health Med. 2012;18(2):19-24.

15. David JM, Sullivan MA. The Relationship Between Opioid and Sugar Intake: Review of Evidence and Clinical Applications. J Opioid Manag . 2010;6(6):445-52.

16. Al-Qabandi M. Gorter JW, Rosenbaum P. Early Autism Detection: Are We Ready for Routine Screening? Pediatrics. 2011;128(1):e211-7.

17. Jenson WR, Rovner L, Cameron S, Petersen BP, KeslerJ. Reduction of Self-Injurious Behavior in an Autistic Girl Using a Multifaceted Treatment Program. J Behav Ther Exp Psychiatry. 1985;16(1):77-80.

18. Peng X, Xu X, Li Y, Cheng L, Zhou X, Ren B. Transmission routes of 2019$\mathrm{nCoV}$ and controls in dental practice. Int J Oral Sci. 2020; $12: 9$.

19. Moynihan PJ, Kelly SAM. Effect on Caries of Restricting Sugars Intake: Systematic Review to Inform WHO Guidelines. J Dent Res. 2014;93(1):8-18.

20. Lima MES, Barros LCM, Aragão GF. Could Autism Spectrum Disorders Be a Risk Factor for COVID-19? Med Hypotheses. 2020;30:144:109899.

\section{Mini Curriculum and Author's Contribution}

1. Fernando José Camello de Lima - DDS; PhD. Contribution: Effective scientific and intellectual participation for the study; data acquisition; draft of the manuscript and final approval ORCID: 000-0003-1593-7747

2. Valdeci Elias Santos Júnior - DDS; PhD. Contribution: Effective scientific and intellectual participation for the study and critical review. ORCID:0000-0001-9748-5830 3. George Azevedo Lemos - DDS; PhD. Contribution: Effective scientific and intellectual participation for the study and data acquisition. ORCID: 0000-0002-2140$216 \mathrm{X}$

4. Olavo Barbosa de Oliveira-Neto - DDS, PhD student. Contribution: Effective scientific and intellectual participation for the study; preparation of the manuscript. ORCID: 0000-0003-1280-659X

5. Christiane Calheiros Farias de Lima - MD. Contribution: Effective scientific and intellectual participation for the study; data acquisition, critical review and final approval ORCID: 0000-0002-7664-5521

Submitted: 09/20/2020 / Accepted for publication: 09/27/2020

Corresponding author:

Fernando José Camello de Lima

E-mail: fernando.camello@hotmail.com 